\title{
Primary schoolchildren's experiences of participatory theatre in a heritage site
}

\section{Vasiliki Tzibazi}

There is a growing need for articulation of the theoretical framework underpinning performance as a learning medium in heritage sites and for an in- depth insight into the children's experiences therein. The aim of this paper is to explore some of the themes that emerged from researching participatory theatre in a historic house as experienced by two primary school groups. The methodology drawing upon the principles of participatory research with children and a constructivist theoretical framework employed interviews, observations and drawings as data generation methods to explore the children's individual and collective experiences. The research findings underline the interplay between the events' theatrical and interpretive format and advocate the significance of children's co-authorship of such events.

Keywords: children; heritage and learning; performance; interpretation; theatre; meaning making; constructivism

In the UK, on a governmental level, school trips to heritage sites are seen as an opportunity to 'bring history alive' and promote powerful learning experiences. The Learning Outside the Classroom (LOtC) Manifesto urged primary schools to embed heritage visits more systematically in their learning/teaching practices (DfES 2006). Henley's (2012) review on Cultural Education in England commissioned by the Department for Education and the Department for Culture, Media and Sport highlighted the value of children's involvement with cultural activities and active experiencing of an event or place including heritage sites, museums and galleries. ${ }^{1}$ Primary school visits to heritage sites often involve participation in a wide range of interpretative activities including hands on tasks, dressing up, guided tours, role- play/drama or participatory theatre, re-enactments and set performances. Although participatory theatre is an established form of educational provision for school groups in historic houses, its complexity as a learning medium is yet to be fully explored.

There is a wealth of literature focusing on the development of theatre as an interpretive medium, in particular in North America and the UK, documenting the various terms under which it is presented and the variety of forms it takes (Risk 1993; Cannizo and Parry 1994; Ford 1998, 2000; Hughes 1998; Maloney and Hughes 1999; Goodacre and Baldwin 2002; Bridal 2004; Tzibazi 2009). The variety of terms and forms that one can encounter reflects the diversity of its use in original historic sites, science centres, zoos, aquariums, museums and galleries. 'Museum theatre' and 'interpretive theatre' are umbrella terms more commonly used in bibliography in the field and professional groups to describe theatrical forms of events that scripted or improvised aim to engage visitors conceptually in the interpretation of objects and/or sites. They encompass programmes of costumed or character interpretation such as the first and third person interpretation events which have prominent theatrical elements and focus on the interaction with the visitor rather than merely on 'giving life' to static exhibits. Within the wider terms of 'museum or interpretive theatre' are also located role-play and participatory events which are conceptually rooted in the drama and theatre in education movements. Although it can be argued that in heritage sites and museum spaces the boundaries between audience and performance could be blurred (Wallace 2007; Leahy Rees 2011), the degree of the visitor's engagement in the theatrical event is what differentiates participatory theatre from other forms of living history programmes. ${ }^{2}$

Institutions such as English Heritage and the National Trust have established a tradition of using various forms of live interpretation as part of their educational provision for school groups (Mayo 1993; Woodhead and Tinniswood 1996). Participation in such 
programmes is often advocated as a medium to experience life in the past and to bring history alive. The wide offer of programmes of role- play and performances within the context of historic houses might be associated with the interpretive strength of historic houses as dwellings and museum objects per se (Young 2007). As dream spaces historic houses provoke visitors' imagination and emotion facilitating connections with personal and collective memory (Risnicoff de Gorgas 2001). Bagnall's (2003) qualitative interviews in heritage settings demonstrate that visitors' life histories, emotions and cognitive constructs shape their heritage experience. Visitors are both consumers and active reflectors of the messages the setting elicits. Not only they bring their own lived experience within historic houses but also through visitation they remember and affirm their social and cultural place in the world (Smith 2006). Of course, children are an audience that is not exempted from these interpretive processes. Leach (2011) conducting research with 8- to 9-year-old school groups reported that students use to a great extent historical and personal narratives to create recollections of their house visiting experiences.

\section{Evaluations of interpretive theatre}

The need for research on how interpretive theatre contributes to the visitors' and in particularly to children's learning experiences is clearly voiced in past research/ evaluations in the field.

The first publicised evaluations conducted for pioneer museums in North America ${ }^{3}$ tended to have semi-experimental and quantitative elements in their design focusing on behavioural, cognitive and emotional aspects of the experience without, always reflecting on the style of the theatrical event they evaluate (Miller 1988; CMC 1993; Munley 1993; Black and Goldowsky 1998; Baum and Hughes 2001). They provide evidence of the effect that the medium has with its immediacy and intensity on the visitors' understanding of the interpreted theme and attempt to 'measure' the behavioural traits of the experience (e.g. holding power/attracting power to exhibits, time spent in the gallery). Given that key aim of these evaluations was to test hypothesis in regard to the cognitive, attitudinal and behavioural impact that the event could have on visitors, including groups of children, one could suggest that the visitors are positioned in these evaluations as subjects/objects and not as 'active participants' who provide detailed and valued personal accounts (Alderson 2004, 100).

A shift in the focus from the impact of the programmes to the nature of the interaction between visitors' and the actors was noticed in the one of the first evaluations conducted in the UK at the Science Museum in London (Bicknell and Fisher 1993). It was reported that although $90 \%$ of the visitors felt that the actors facilitated understanding of life in the past and made the exhibits more memorable, almost half of the visitors who participated in the research, depending on their familiarity with the discussed topic, felt embarrassed and uncomfortable to interact with the actors (Bicknell and Fisher 1993). The same research also suggested that children are more eager than the adults to participate in events while further research was recommended to examine processes of learning and suspension of disbelief (Bicknell and Mazda 1993).

However, although the need for further research with children was pointed out right from the first steps of the medium in the UK, the evaluations museums and heritage sites conducted with school groups tended to have the format of questionnaires completed by class teachers and thankful letters posted to the museums. The research landscape in the area of museum learning with school groups might have changed within the UK with the introduction of the standardised generic evaluation framework for museums 'Inspiring Learning for All' and the challenge that museums face to provide evidence for their cultural and educational role. However the evaluations, due to the nature also of the framework, tend to take place on an ad hoc basis focusing on specific aspects of the experience (e.g. enjoyment) and its initially stated educational objectives. 
Children's perceptions of the medium, and in particular of first person interpretation in museums, are illustrated for first time in recent research that moved beyond quantifiable measures of the experience (Jackson and Rees Leahy 2005; Jackson and Kidd 2008; Tzibazi 2009). A semi-experimental and qualitative research aiming to trace the effectiveness of the medium indicated that theatre 'can be a powerful interpretive tool' that encourages 'closer attention to narratives, objects and environments' without promising a holistic view of history (Jackson et al. 2002, 320-1). Children attribute authenticity to the objects and performances they encounter at the museums and they recall vividly the narratives associated with the performances (Jackson et al. 2002). Further research on the reading of first person interpretation events has shown that the extent to which the children attribute authenticity and read the narratives as a source of historical information depends on the actor's plausibility as a fictional character and the performance's strong theatrical elements. Only when the children suspend their disbelief, they also accept the narrative as a plausible representation of the past (Tzibazi 2009). Such researches, mostly focused on first person interpretation events, demonstrate that the medium can facilitate the interpretation of collections and open the space for further enquiry regarding children's meaning making of other types of theatrical events in a range of settings.

\section{The aim of this research}

This research, influenced by the paradigm for childhood studies research that views children as social actors and not merely as beings in the process of becoming adults (James and Prout 1997; Christensen and James 2008), aims to explore how school children experience both the format and interpretive content of a participatory performance in a historic house. Two theatrical events are explored that take place in the heritage site 'Clarke Hall' in North England with the participation of two randomly selected primary school groups, a year 4 class (aged 8-9 years) and a year 6 class (aged 10-11 years). The investigation of children's perceptions is not a new idea in educational research especially with the flourish of the pupil voice movement that emphasises the importance of researching the reality as experienced by children in educational settings rather than making assumptions about their own experiences (Cox and Robinson-Pant 2008). Within the context of this research, the viewing of the participatory performance via the children's perspectives might offer an insight into the potential of the medium as an interpretative tool and highlight the parameters that need to be taken into account when participatory performances are designed as learning mediums in heritage sites.

In line with the constructivist stance that views interpretation not as a replication of an intended meaning but as process of knowing that 'involves experience, the coordination conceptual structures, and symbolic representation' (Glasersfeld 1983, 207), the children are positioned in the research as active meaning makers who bring to the interpretation of the performances their own expectations, values, reality and learning agendas. The very act of interpretation of the theatrical events is seen as part of the children's immediate experience of the event directly associated to their own experiential world within which the new constructs make sense or to use the constructivist terminology are 'viable'. Constructivism as a theory of knowing discarded the notion that interpretation should be the representation of an external objective world with the demand that the conceptual constructs we call knowledge should 'be viable within the knowing subject's range of experience' (Glasersfeld 1989, 125). Therefore, we cannot take for granted that we all share automatically the same construction of meaning when interpreting something or even communicating. In the communication process, we formulate interpretations that are viable within one's and also each other's understandings. It is via successive interactions that we test each other's meanings for relative compatibility and accordingly, we modify our conceptualisations to reach a conventionally established 'consensus' or in other words a 'shared' experiential world (Glasersfeld 1983, 216). Within this context, the theatrical event as any other 'object' of interpretation does not exist independently 
of the interpreters' notions, concepts and re-presentations they bring to the experience. The theatrical event is shaped via the interactions of the participants including the interpretations, expectations and agendas of the professionals who designed and delivered the theatrical event.

Thus, the research took also into consideration the interpretations and agendas of the school teachers and the museum theatre professionals to trace when appropriate relative compatibility or clashes in the multiplicity of meanings. This enabled the examination of the reading of the events not as a distinct entity occurring merely within the children's imagination but as a product of relationships among the involved readings and agendas. In order to obtain an insight into the range of experiences and understandings related to the interpretation of and communication during the event, the research unfolded in three stages (before, during and after the event). Two months were spent overall with each class to explore their agendas prior and following to the visit to the heritage site while given that meaning making evolves through time and further experiences each class was revisited in six months following the event.

\section{The event}

The theatrical event was selected for its participatory format and the site's long tradition in providing living history programmes for school children.

Clarke Hall is a 16th century building which at the beginning of 70 s was restored as a living history museum echoing both the new education movement that spoke for selfexpression and child centeredness, and the emphasis placed at the time on the use of the country's heritage as an educational resource for organised school groups (see Harrison 1967, 1970; Dyer 1986). More than 6,000 pupils visit the site every year to participate in the educational sessions; the staff dressed in costume and pretending to live in the past welcomes the groups of mainly primary schoolchildren who dressed also in costume participate in handson activities to experience life in the given historical period.

Participatory performances also take place due to the staff's intention to offer an educational programme that would enhance children's classroom-based learning. The museum educators advocate the children's verbal participation in the participatory performances. A fictional scenario functions as a skeleton of the event of participatory performance without however having the format of a scripted dialogue. This fictional scenario usually takes the following format; the children arrive at the heritage site pretending to be entertainers that are on the way to London to perform for the King. They knock the Hall's door to ask for the house owner's permission to rest for a while. During their visit, they meet five characters: the owner of the house and her two cousins, a soldier (who is searching for someone who stole a lantern) and a traveller who is asking for work at the Hall and has amongst his possessions a lantern. The children are divided into groups to perform tasks according to their role. The visit ends with a debate between the children that argue that the traveller is the thief the soldier is looking for and the children who defend him from the accusations.

\section{Methodology}

\section{Conducting research with children}

This is a small-scale qualitative research conducted with the participation of 30 children, their class teachers and the staff involved in the theatrical event. The methodology positioned under the realm of the interpretivist/constructivist paradigm viewed the participants in the event as intentional actors who interpret their own and others' actions (Smith 1989; Schwandt 2003). 
In particular, by positioning the children as 'active participants' that 'should be informed, involved and consulted about all activities that affect their lives', a number of issues were taken into account including the gaining of the children's informed consent, the design of appropriate methods and the address of issues of confidentiality, anonymity and power (Robinson and Kellett 2004, 86).

The access to the field was initially negotiated via the gatekeepers (school, parents/ carers) while the final decision for participation in the research lay with the children. The research aims and processes were explained in detail first through a whole class discussion and then in small groups. By taking into account that researchers have expressed doubts about the children's power to refuse further involvement at all stages of the work (Lindsay 2000; Harcourt and Conroy 2011), the children were asked for their written informed consent at each stage of the research allowing them to withdraw at any time from the study. Following the British Educational Research Association Guidelines (2011), children's anonymity was safeguarded throughout the research and the boundaries of confidentiality were openly discussed.

Power imbalance between the researcher and the researched is a key issue in any research context. The question 'what does it mean to be seen as a researcher' was posed right from the start: was I seen as an adult and a neutral stranger? As pointed out by Mayall (2008), generational issues cannot be defused to the point where children see the adult as equal. Rather than downplaying on the issue of power, I directly discussed my researcher identity and status in the classroom (ibid.). Five days a week for a month was spent in each class to establish rapport with the children and to familiarise my self with the class's agenda; to understand the class's experiences and expectations regarding museum visiting and preconceptions about the historical period in question. I joined in all activities in the classroom and the playground and when appropriate I worked as a general helper without however exercising any kind of authority in the classroom. This approach might have facilitated the building of 'truthful' relationship with the children and the eliciting of genuine data. However, it did not transform the children's status from active participants into equal collaborative partners since the decision of what would count as data remained with the researcher. Although the children were consulted about the data interpretation, my role as a researcher in the data generation was central. It was within my interaction during the course of inquiry that data were generated. This is a key issue especially within the interpretivist perspective that views the researcher and the process of inquiry as inseparable from what is or can be known (Smith 1989).

\section{Data generation methods}

A range of qualitative data generation techniques was employed such as participatory observations in the museum and the classroom setting, children's individual and group drawings, group interviews before and following the classes' participation in the event and individual interviews six months after the event.

\section{Participatory observations}

The selection of observation as a method of generating data was based on the research's qualitative interpretivist viewpoint and ethnographic features including the emphasis on the social nature of the phenomenon, the tendency to work with unstructured data and the investigation of small number of cases (Atkinson and Hammersley 1998).

In particular, being a 'participant-as-observer' in the school groups' activities both at the school and the heritage setting allowed me to collect first-hand data by gaining a perspective in the situation as an active, reflective participant (Adler and Adler 1994, 379). This stance allowed 
me to be present and conceptualise these interactions within their natural setting as they occur rather than rely exclusively on their post hoc reconstruction via the participants' accounts. Literal, interpretive and

reflective notes of my own experience of the theatrical events were kept, and audio recording was used to provide transcriptions of verbal interaction. Although the data were gathered openly without generating hypotheses, the observations focused on the participants' verbal and non-verbal communication: facial expressions, body language and movement. Peripheral participation in the school life allowed me to become an insider at all stages of the event attending the heritage sites' preparatory sessions for schoolteachers, collecting relevant documentation, creating narrative accounts of the lessons and activities that were directly related to the event. Within the school setting, by taking into consideration that written ethnography entails the risk that the researcher will see the aspects of classroom practice that he/she is familiar with, certain aspects were also taken into account: the lessons' objectives, the nature of the learning tasks, the use of teaching-learning aids and the aspects of hidden curriculum (spatial arrangements, behaviour, class's visual data). The children's responses in the class context were recorded in detail and they were seen not as a reaction but as a transaction with the teacher.

\section{Children's drawings}

Children's drawings were used to offer an insight into the children's meaning making of the experience and show possible aspects of tacit learning that would not be available through other data generation techniques. It was expected, in line with the findings of researches that used visual methods in school ethnographies, that children's drawings would be an inclusive medium that gives voice to children and facilitates the articulation of their thoughts and feelings (Fasoli 2003; Ruddock and Flutter 2003; Kaplin and Howes 2004; Cappello 2005). In this research, children's drawings were used within different contexts following the participation in the drama event: (a) immediately after or the following day of their museum visit, (b) during the group interviews and (c) at the individual five-months-after interviews. Given the subjective nature of the medium, the drawings were interpreted in relation to the children's comments on their drawing that were expressed during and/or following the activity. Adequate time was given for the activity while by taking into account that children at the age of eight and older might feel intimidated to draw, it was emphasised that the children should feel free to participate in the activity without being troubled about the outcome from an artistic perspective (Thomas and Silk 1990, 39). When children commented that they drew something because it was easy, the actual drawing did not count as data. Perhaps it is also worth noticing that when children were asked for their consent to participate in the drawing activity, not all children were willing to participate contrary to the assumption that drawing activities in research are popular and enjoyable amongst children.

Individual and group drawings were also used as a research tool during the follow-up interviews. During the group interviews, the children were encouraged to produce a collective drawing regarding the drama event as if they were preparing illustrations for a book. The activity facilitated the narration of key aspects of the event, provided a context for open-ended questions regarding the children's meaning making (e.g. who, what, when) and assisted with the children's interaction within the group context. The children who participated in the individual five-months-follow- up interviews were also encouraged to 'make a drawing' related to the event. The decision to incorporate drawings at this stage of research was influenced by the findings of Butler, Gross and Hayne (1995) research which suggests that participation in drawing activities can facilitate the recalling of events. 


\section{Group interviews}

According to Fontana and Frey (2005), unstructured group interviews can aid the research participants recalling of specific events and stimulate elaborate descriptions of events or experiences shared by the group. As a method, within the context of this research, it facilitated a natural way of talking that gave 'thinking time' to the group and a supportive environment for less confident children (Lewis 1992, 417). The purpose of the interviews was to obtain an insight into the class's agenda prior to the visit and following the participation the theatrical event. The open-ended questions aimed to trace the participants' expectations, experiences of drama and museum visits, understandings and preconceptions about the period in question and emerged as a logical progression of the discussion. The group interviews, conducted with a great degree of flexibility, allowed me to give and ask for clarifications, interpret the meaning of the responses and ask for the participants' feedback to my interpretation. They offered an insight into the 'taken-as-shared' aspects of the children's experience and interpretation of it.

\section{Key research themes}

Each class visited the heritage site having its own agenda. For the year 6 class, it was expected that the event would stimulate the children's imagination and as a result would improve their writing skills. As part of their preparation for the visit, the children participated in an improvisatory drama, researched the relevant historical period and expected that the created narrative would continue at the setting. On the other hand, the year 4 class did not participate in any preparatory activities. They decided to visit the site for its potential to offer a first-hand living history experience. The children expected that they would visit a museum about Tudors.

The main themes that emerged from children's responses for both events suggest that there is interplay between the children's learning experiences and the medium's theatrical and pedagogical form.

\section{The unexpected}

Unexpected moments in the event created tension and established the children's belief in the events' fictional context. The children's reflections suggest that the unexpected entrance of new characters and the children's welcoming within an 'as if' context affected the children's belief in the theatrical event.

One of these moments takes place right from the start of the event. When the school groups arrive in the historic house dressed in costume, the class teacher knocks on the Hall's door two or three times without receiving a response from inside. Finally, when the museum educator opens the door hesitantly she addresses the group directly in role:

Actor: Who is this travelling company knocking at my door?

Class teacher: We are travelling to London, we are entertainers that want to perform for the king.

Actor: You must be tired, it's rather a cold day. Why don't you enter for a while to rest

and then you have to be on your way ...

Both groups' responses indicated that the element of the unexpected correlates with the classes' expectations for the visit. The fact that there is not an immediate response and that the owner of the house does not 'recognise' them created a powerful moment for the year 4 group. There was a mismatch between the text (what is actually happening in the event) and 
the children's subtext (their expectation that the door will open and they will enter a museum). The first encounter with the actor addressing them directly in role shares similarities with the teacher in role technique that is used in drama to facilitate the suspension of disbelief. It operated as a 'pre-text' that '[switched] on expectation and [bound] the group together in anticipation' (O'Neil 1995, 20). The following responses from the group interviews illustrate this point:

Emily: When we knocked the door I was scared.

Scott: I was nervous I did not know what would happen. Laura: I felt I was properly in that part like in

Tudor times. (Extract from group interviews, year 4).

The year 6 class being in role due to the preparatory session at school appreciated the element of the unexpected from a functional view within the fictional context. The children, being aware of the dramatic character of their visit and willing to participate actively within the new situation, acknowledge the function of the unexpected and accept it. Their willingness to share the context set by the author (in this case the museum educator) is indicative of their suspension of disbelief, which is a basic component of educational drama (O'Toole 1992; Anderson 2011):

Steven: Because this is what it was supposed to happen.

James: This is important to make it seem like Tudor times, to close the door. It is important ...

Zoe: to turn us down.

(Extract from group interview, year 6)

Similar comments were also expressed for a moment of tension when a new character entered unexpectedly the setting:

Darcy: We were talking about what we would be doing and there was this great big knock on the door and we were frightened.

Laura: I was scared the worst. Why on earth is that soldier in that woman's garden? Was it only us and him over there? He is a worker that he came from the front door. Was he in the garden? I thought... this is strange. We were there, in the story, and did not know what would happen ...

(Extract from group interview, year 4).

\section{The contract}

One of the prerequisites for educational drama is the establishment of a contract that will make clear the demands made of all participants by the learning situation. The contract drawn up with the children may be negotiated and revised as the drama unfolds. When a contract is not explicitly set, the children decipher the signals available such as the 'teacher's language, questioning, decision-making, forms of individual and group negotiation', as indications of who will make decisions about the learning agenda (Neelands 1984, 31). During the researched events, it was only when the children were encouraged to negotiate the fictional action within the event that they improvised and commented on having ownership of the action. The following extract is taken from the narrative when engaged in collective drawing: 
Joshua: I was feeling like a detective, Priscilla [the owner of the house] trusted us and I wanted to find out the truth

James: He was going to tell us a story and we agreed that if he can tell us about his life we could then make a story. [.. . ]

Andrew: We were soldiers ...

James: I was master James ... I give orders and .... .

Joe: We did them . . . like when we are outside looking through the window, we shot what?

And then it was me and Hanna

Hanna: Yes we walked down the corridor. We were searching for the one that looks guilty.

Joshua: They were looking through this hole in the barn. It was Hanna wasn't it? Hanna: [nodding] James: And then Joe was sitting out there ....

$[\ldots]$

(Extract from group interviews, year 6, see also Figure 1)

During the event it was noticed that in the absence of an explicit power-sharing contract, the children's responses altered when the class teacher and teaching assistants participated in group work as spectators. The school contract was prominent and their power status was maintained during the event tacitly shaping the children's behaviour and responses. The children would put their hands up to
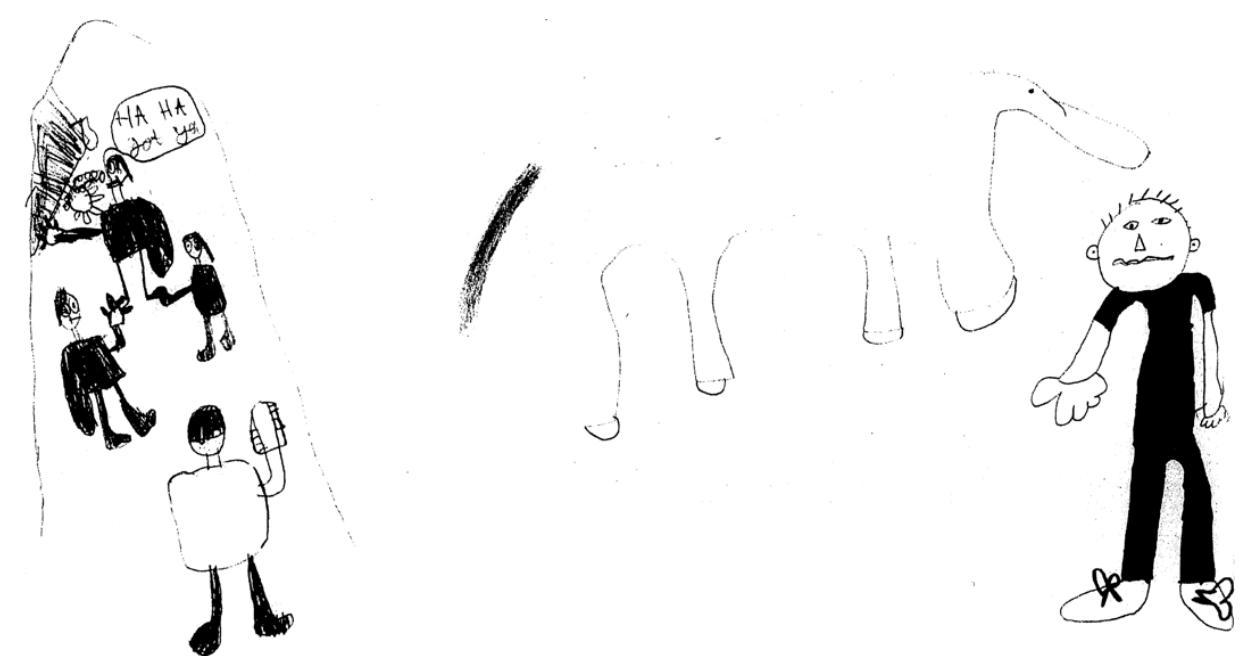

Figure 1. Collective drawing, year 6.

reply to the actors' questions and acknowledge the teacher's presence during the event. The following comment elicited from an interview that was conducted six months following the event (year 4) illustrates the implicit role that teaching assistants had during the event: 
Charlotte: Ms B . . came with us. She works in year two but she came with us. She is Robert's mum.

Me: And was she with the storytellers group?

Charlotte: She was the boss in the story because always in groups she is the boss.

Me: Did she speak in the story?

Charlotte: Yes, because she said child $x$ says this and another one says that $\ldots$ and she saw if we were good.

The children's responses, such as the one above, suggest that the school frame still operates during the event and affects the quality of children's participation in the event. The necessity for teachers' professional development in aspects of outdoor learning is highlighted in relevant studies (Humberstone and Stan 2011; DeWitt and Storksdieck 2008). Perhaps this need becomes more evident within the context of participatory theatre since the presence of the school staff compromises the children's experimentation with new ideas and values within the safety net of the fictional context.

\section{Authenticity: setting and objects}

When reflecting on the experience children's comments included frequent references to the setting, its objects and the group's movement within the Hall:

Hanna: It's like stepping into another dimension when you go in there because it is so old.

Joe: It was very old. They had wooden things but they were not like today. They had long wooden tables.

Joshua: and then our class gathered around the table, and the owner of the house asked us if [. . .]

(Group interview extract, Year 6).

Chelsea: [while drawing] we passed through the first door and then there was another one . . . quite strange as we don't have now houses with two doors ... by this was a Tudor house (year 4).

The children viewed their museum visiting experience as an opportunity for learning and valued the setting and the first-hand experiences that unfolded within it as authentic. In particular, the year 4 class whose agenda prior to the visit was orientated towards history learning without including any expectations for participation in a theatrical event, interpreted their experience of having breakfast around the Hall's kitchen table as a first-hand Tudor experience. The furniture and the objects were valued as 'real' Tudor objects and were memorable five months after (see Figure 2):

Laura: because it is so different the meal table and different seats and biscuits. It is all about Tudor time, interesting facts, what they were doing at Tudor time when they were eating (year 4 - comment on drawing). 
The children's expectations of participating in historically authentic experiences pose questions about the historical context within which the first-hand experiences are offered. Debates about the nature of interpretive theatre as a medium that could trivialise history might have been resolved amongst the circle of museum professionals (Alsford and Parry 1991; Cannizo and Parry 1994; Ford 1998). Nonetheless, the development of well-researched events will always be of paramount importance. The provision of experiences within the historical context should not only be limited to the selection of the objects presented during the experience and the use of costumes, but should also be expressed within the performative context and narratives of the event. Given that historical narratives are the most frequently recalled narratives in children's recollections of visits to historic houses (Leach 2011), it was expected that within a fictional context the children's references to historical narratives would be dominant. The fictional narratives focusing on human experience could have offered an opportunity for the exploration of interpretative material grounded in the period in question. However, the characters are read in association only with the story's fictional plot unless the children already had background knowledge about the social division in the historic period. For example, the year 4 children do not seem to take into account that the character of the owner of the house was a representative of the wealthy class. They recreate a historical context that draws entirely on their own explanatory frameworks, whereas, if these constructions are not challenged during or after the museum visiting experience, they seem to be viable in the long term. The following extract suggests that they interpreted the owner of the house as a 'poor' person and accordingly made deductions about the status of living and housing in the period in question:

Nathan: in the books they show that poor people were living in thatched houses. This cannot be real. Priscilla was living in a house better than mine, like a palace.

You have to see the bedrooms they have got, it's like a palace compared to ours. (Interview extract, six months following the event, Year 4).

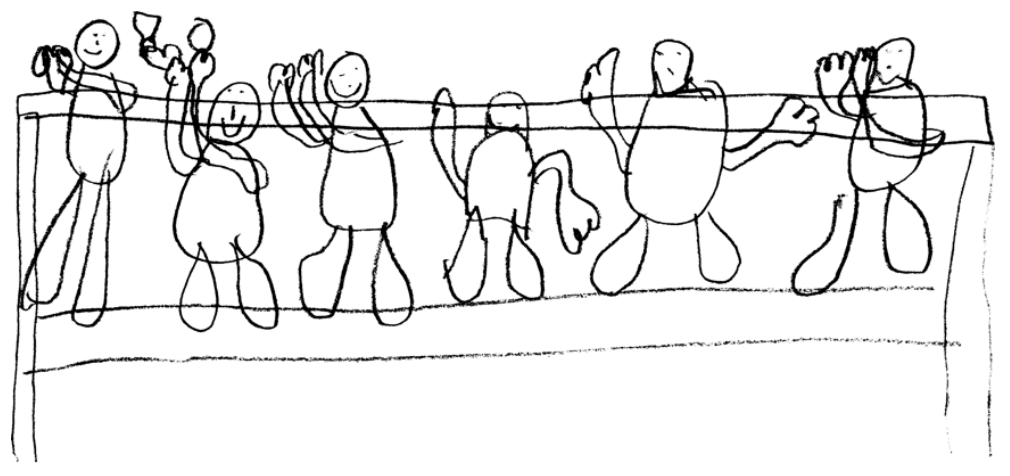

Figure 2. Individual drawing, year 4. 


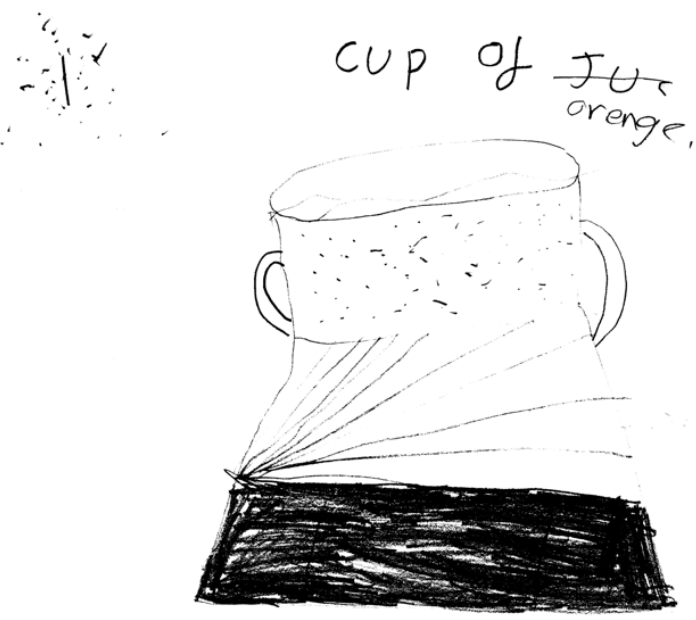

Fure 3. Individual drawing, year 4.

\section{Framing participation and meaning making}

Children's meaning making of the event's fictional story seems to be guided by the event's framing and the children's positioning within the framed action. Jackson (2007) suggests that framing strategies applied in theatre events affect the participants' generated meaning. Indeed, there is a double dramatic framing of the event that presents the event to two groups of participants from a different narrative viewpoint with the intention that this difference would stimulate the children's debating. In one group, the message the actor/museum educator intends the children to construct is that 'he is an honest man, mistreated in life, poor and homeless'. The children are endowed secretly by the owner of the house with the role of investigators to discover the truth about the traveller. They question the character who through storytelling and the use of objects, narrates his life. The second group of children endowed also with a fictional role participate in a storytelling session that led by the actor intends to set up a moral that emerges from the character's personal story: as a soldier he has been tricked in the past so he does not believe people's stories for sympathy anymore. In the final act of the event, all the participants meet together and the two groups are positioned within an 'involvement frame' (Jackson 2007) in the centre of the action either to accomplish a task (e.g. to interrogate the traveller) or to influence the action as the event unfolds (i.e. to prove to the rest of the class that he is innocent).

The children's comments both immediately after and six months following the event suggest that they interpreted the fictional plot and the characters' roles as it was intended by the actors. The meaning was constructed through their own involvement in the action and reading of the clues that were provided by the characters. The following extracts from the group and individual interviews might illustrate these points:

Jonathan: In the fire in the kitchen when the soldier came in from the garden

Darcy: If he is not guilty how can he be hiding himself?

Mary: [nodding] 
Jonathan: He was sat next to the fire and when the soldier came in he moved to the other side of the room

Darcy: When the soldier said we are looking for someone that stole a lantern he put his hat down and he moved next to you.

(Extract from group interview, year 4)

Researcher (R.): what happened in this group?

Andrew: He was trying to make us believe that he did not do it. And some people believed that he did do it and some people believed that he did not do it and then some people thought he did do it and some people thought he did not do it.

R: from your group?

Andrew: From my group and then they showed us to try to make us believe him. I did not believe him from the beginning.

$\mathrm{R}$ : what was that that made you change your mind?

Andrew: When he got right through the story and he kept telling us about the story [ . . ] He showed us some horse shoes and some nails, a spoon and a plate that he got because he saved that man. He said that he used to be a blacksmith and he had to give up his house to pay tax. His dad died. And then he told us a story when he was working for Mr Brown. Oh, no when he was working for a farmer close to Mr Brown and he had his lantern with the stars and [. . . ]

(Extract from individual interview, year 6)

If one turns into Wolfgang Iser's reception theory which postulates that the reader-text relationship evolves around the gaps stimulated by the blanks on the text, then questions can be posed about the events' potential to encourage children to act as self-reflectors in the construction of meaning. According to Iser (1980), the reader's activity is controlled by the guiding devices that operate in the reading process, which although they do not reside in the text, are exercised by it. In the reading process, the gaps in communication stimulate the reader into filling them with projections. In a way what is said obtains greater significance by what it is not said. The implications of what remains concealed stimulate the reader's imagination and give weight to the meaning. Communication becomes an 'interaction between the implicit and explicit, between revelation and concealment' (Iser 1980, 111). Thus, the reader is constantly constructing hypotheses about the meaning of the text, making implicit connections and testing out hypotheses. In a way, the text itself is no more that 'a series of cues to the reader', which the reader puts together to fill the gaps and construct hypotheses (Eagleton 1996, 66).

The children's meaning making reflected the actors' intended messages and was transferred by analogy to the class's everyday context. For example, the year 6 children who defended the traveller in front of their peers by reflecting first on their initial belief that the 
traveller was guilty just because of his 'suspicious' behaviour, and then on the outcome of final part of the event (i.e. that there was not any actual evidence against the traveller), transferred this dramatic situation, by analogy, to their everyday context. These comments were elicited in an individual interview six months following the event:

Steven: I learned that you should not accuse people when you do not know if they have done it or not. Because you do not know if they have done it if somebody else told you that they've done it.

(Extract from individual interview, year 6)

Emily: I think they were hard on people sometimes. I think they were accusing people without being sure. Some people might accuse others without knowing really, like Tudor times. So, the best is to be honest and to tell if you know who exactly is.

(Extract from individual interview, year 4)

Accordingly, the children who participated in the storytelling session with the soldier embraced the intended message:

Nathan: I learnt that when somebody knocks on your door and tells you stories that he needs your help you should not listen to his stories.

(Extract from individual interview, year 4)

To which extend the events' format is negotiated, even when the children are willing and prepared to act within the fictional context? In both events, the fictional action unfolds along similar lines and children are positioned as passive recipients of predetermined messages. The resolution in the fictional plot/action is predetermined by the adults: the traveller is provisionally arrested by the soldier. Hence, to borrow a term from Eco's (1984) semiotic analysis, the events might be characterised as 'closed' texts given that they pulled the reader towards a set path for 'meaning making'.

\section{Concluding words}

Although this is a small-scale research, it provides a critical perspective into the way children experience participatory theatrical events in historic houses. Irrespectively of the class's preparatory agenda, children view the events and the heritage site as a learning opportunity to actively experience life in the past. The generated data suggest that children attribute to the whole experience authenticity and focus on the setting itself, the objects and the fictional narratives. Children read the story's fictional plot through their background knowledge and constructs about the period in question. When these constructs are not historically and politically informed, the theatrical event is read by what seems to be tangible and immediately accessible to the participants (e.g. costumes, objects). Children tend to create their own explanatory frameworks via comparisons between what is considered to be the past and their present experiences and everyday reality. This interrelation between the ideas explored in the fictional context and children's reality is not unaffected by the participatory and theatrical format of the event. Unexpected moments of tension, framing of participation and establishment of a contract via negotiation are few of the elements that shape children's meaning making of the events. Future research with other audience groups (e.g. families, 
community groups) could yield further insights into the processes of meaning making of interpretive theatrical events.

If visits to heritage sites and participation in interpretive theatre events are aspired to offer powerful learning experiences and be more systematically embedded in primary school's curriculum, teachers and museum education professionals need to design collaboratively such events. Consideration needs to be given to the theatrical format of the events ensuring that multiple layers of meaning (e.g. personal, historical, social, political) which reflect the complexity of the human experience are interwoven in the fictional narratives. Children need to be given opportunities to articulate their thoughts and feelings about the events' interpretive content and critically examine the truths and beliefs that are hidden or integrated in the narratives. Even if follow up and preparatory work with the school groups could offer opportunities for reflection, reflection should not be only corollary of the events but primary to the events' pedagogical format. All professionals involved in the planning need to share a common understanding of participatory theatre's pedagogy that positions children as coauthors who within the fictional context freely explore ideas, shape the events and re-articulate through their own eyes their viewing of and positioning in the world.

\section{Notes}

1. As a response, following an earlier reduction in grants, English Heritage was awarded $£ 2.7 \mathrm{~m}$ by the Department for Education to develop the 'Heritage Schools Initiative' aiming to help children understand areas of local significance and how they relate to English history (English Heritage 2012).

2. For example, re-enactments are known for their non-verbal interaction with the visitors and performative nature (Robertshaw 2006; Sansom 1996).

3. Such as the Science Museum of Minnesota, Canadian Museum of Civilization, National Museum of American History and the Museum of Science in Boston.

\section{References}

Adler, P., and P. Adler. 1994. Observational techniques. In The handbook of qualitative research, ed. N.K. Denzin and Y.S. Lincoln, 377-91. Thousand Oaks: Sage.

Alderson, P. 2004. Ethics. In Research with children and young people, ed. S. Fraser, V. Lewis, S. Ding, M. Kellett, and C. Robinson, 97-112. London: Sage in association with Open University.

Alsford, S., and D. Parry D. 1991. Interpretive theatre. Museum Management and Curatorship 10: 8-23.

Anderson, M. 2011. MasterClass in drama education: Transforming teaching and learning. London: Continuum Publishing Corporation.

Atkinson, P., and M. Hammersley. 1998. Ethnography and participant observation. In Strategies of qualitative inquiry, ed. N.K. Denzin and Y.S. Lincoln, 110-36. London: Sage Publications.

Bagnall, G. 2003. Performance and performativity at heritage sites. Museum and Society 1, no. 2: 87-103.

Baum, L., and C. Hughes. 2001. Ten years of evaluating science theater at the Museum of Science, Boston. Curator 44, no. 4: 355-66. 
Bicknell, S., and S. Fisher. 1993. Enlightening or embarrassing? Drama in the Science Museum, London, United Kingdom. In Visitor studies: Theory, research and practice (Collected papers from the 1993 Visitor Studies Conference Albuquerque, New Mexico), vol. 6, 79-87. Jacksonville, Alabama: The Visitor Studies Association.

Bicknell, S., and X. Mazda. 1993. Enlightening or embarrassing: An evaluation of drama in the Science Museum. London: National Museum of Science and Industry.

Black, D., and A. Goldowsky. 1998. Science theatre as an interpretive technique in a science museum.

http://www2.educ.sfu.ca/narstsite/conference/blackgoldowsky/blackgoldowsky. html (accessed May 2, 2003).

Bridal, T. 2004. Exploring museum theatre. Walnut Creek: Altamira Press.

British Educational Research Association Guidelines (BERA). 2011. Ethical guidelines for educational research.

http://www.bera.ac.uk/system/files/BERA\%20Ethical\%20Guidelines\%202011.pdf (accessed April 2012).

Butler, S., Gross, J., and H. Hayne. 1995. The effect of drawing on memory performance in young children. Developmental Psychology, American Association 31, no.4: 597-608.

Canadian Museum of Civilisation (CMC). 1993. Evaluation of the live interpretation program at the Canadian Museum of Civilisation 'Perspectives on Museum Theatre'. In Technical Information Service's Forum: Occasional papers and readings on museum issues and standards, 95-142. Washington, DC: American Association of Museums.

Cannizo, J., and D. Parry. 1994. Museum theatre in the 1990s: Trail-blazer or campfollower? In Museums and the appropriation of culture, ed. M.S. Pearce, 43-64. London: The Athlone Press.

Cappello, M. 2005. Photo interviews: Eliciting data through conversations with children. Field Methods 17, no. 2: 170-82.

Christensen, P., and A. James, ed. 2008. Research with children: Perspectives and practices. 2nd ed. New York: Routledge.

Cox, S., and A. Robinson-Pant. 2008. Power, participation and decision making in the primary classroom: Children as action researchers. Educational Action Research 16, no. $4: 457-68$.

Department for Education and Skills (DfES). 2006. Learning outside the classroom manifesto. Nottingham, UK: DfES.

DeWitt, J., and M. Storksdieck. 2008. A short review of school field trips: Key findings from the past and implications for the future. Visitor Studies 11, no. 2: 181-97.

Dyer, M., ed. 1986. Heritage education handbook. Lincoln, UK: Heritage Education Trust.

Eagleton, T. 1996. Literary theory: An introduction. 2nd ed. Oxford: Blackwell Publishers. 
Eco, U. 1984. The role of the reader. Explorations in the semiotics of texts. Bloomington: Indiana University Press, first Midland Book Edition.

English Heritage. 2012. Heritage Schools: Part of the Government's vision for cultural education. http://www.english-heritage.org.uk/about/news/heritage-schools/ (accessed April 24, 2012).

Fasoli, L. 2003. Reading photographs of young children; looking at practices. Contemporary Issues in Early Childhood 4, no. 1: 32-47.

Fontana, A., and J. Frey. 2005. The interview: From neutral stance to political involvement. In The handbook of qualitative research, ed. N.K. Denzin and Y.S. Lincoln, 3rd ed., 695728. Thousand Oaks: Sage Publications, Inc.

Ford, C. 1998. The "theatre - in - museum" movement in the British Isles. PhD diss., The University of Leeds.

Ford, C. 2000. Interpretation special: Museum theatre. Museum Practice 13, no. 5(1): 62-4.

Glasersfeld E. Von. 1983. On the concept of interpretation. Poetics 12, no. 2/3: 207-18.

Glasersfeld E. Von. 1989. Cognition, construction of knowledge and teaching. Synthese 80, no. 1: $121-40$.

Goodacre, B., and G. Baldwin. 2002. Living the past. London: Middlesex University Press.

Harcourt, D., and H. Conroy. 2011. Informed assent: Processes and procedures in seeking research partnerships with young children. In Young children's perspectives: Ethics, theory and research, ed. D. Harcourt, B. Perry, and T. Waller, 38-51. Routledge: London.

Harrison, M. 1967. Education today: Changing museums, their use and misuse. London: Longmans.

Harrison, M. 1970. Learning out of school: A teacher's guide to the educational use of museums. London: Ward Lock Educational.

Henley, D. 2012. Cultural education in England. An independent review by Darren Hanley for the Department for Culture, Media and Sport and the Department for Education. http:// www.culture.gov.uk/publications/8875.aspx (accessed April 24, 2012).

Hughes, C. 1998. Museum theatre: Communicating with visitors through drama. Portsmouth: Heinemann.

Humberstone, B., and I. Stan. 2011. Outdoor learning: Primary pupils' experiences and teachers' interaction in outdoor learning. Education 3-13: International Journal of Primary, Elementary and Early Years Education 39, no. 5: 529-40. 
Iser, W. 1980. Interaction between text and reader. In The reader and the text: Essay on audience and interpretation, ed. S. Suleiman and I. Crosman, 106-20. Princeton: Princeton University Press.

Jackson, A. 2007. Theatre, education and the making of meaning: Art or instrument? Manchester: Manchester University Press.

Jackson, A., and H. Rees Leahy. 2005. Seeing it for real . . . ? "Authenticity, theatre and learning in museums". Research in Drama Education 10, no. 3: 303-25.

Jackson, A., and J. Kidd. 2008. Performance learning and heritage. Report from the Centre for Applied Theatre Research, University of Manchester. http://www.plh.manchester.ac.uk/ documents/Performance,\%20Learning\%20\&\%20Heritage\%20-\%20Report.pdf (accessed April 24, 2012).

Jackson, A., Johnson, P., Rees Leahy, H., and V. Walker. 2002. Seeing it for real: An investigation into the effectiveness of theatre and theatre techniques in museums. Manchester: Centre for Applied Theatre Research (CATR), University of Manchester.

James, A., and A. Prout, ed. 1997. Constructing and reconstructing childhood. London: Falmer/ Routledge.

Kaplin, I., and A. Howes. 2004. Seeing through different eyes: Exploring the value of participative research using images in school. Cambridge Journal of Education 34, no.2: 143-53.

Leach, D.B. 2011. Children's recollections of a historic house visit: Recall of experiences and use of cognitive tools. Visitor Studies 14, no. 1: 34-47.

Leahy Rees, H. 2011. Watching me, watching you: performance and performativity in the museum. In Performing heritage, ed. A. Jackson and J. Kidd, 26-38. Manchester: Manchester University Press.

Lewis, A. 1992. Group child interviews as a research tool. British Educational Research Journal 18, no. 4: 413-21.

Lindsay, G. 2000. Researching children's perspectives: Ethical issues. In Researching children's perspectives, ed. A. Lewis and G. Lindsay, 3-20. Buckingham, Philadelphia: Open University Press.

Maloney, L., and C. Hughes, ed. 1999. Case studies in museum, zoo, and aquarium theatre. Washington: American Association of Museums.

Mayall, B. 2008. Child-adult relations in social space. In Children, young people and social inclusion: Participation for what, ed. E. Kay, M. Tisdall, M.J. Davis, M. Hill, and A. Prout, 199-215. Bristol: The Policy Press.

Mayo, S. 1993. 'I didn't know I liked history so much' - Reflections on three years with the Young National Trust Theatre. GEM News no. 52: 7-8.

Miller, D.S. 1988. The effect of interpretive theatre on children in the museum setting. MA diss. Statesboro: Georgia Southern College. 
Munley, E.M. 1993. Evaluation study report of Buyin' Freedom. An experimental live interpretation program. In Perspectives on museum theatre. Technical Information Service' Forum: Occasional papers and readings on museum issues and standards, 69-94. Washington, DC: American Association of Museums.

Neelands, J. 1984. Making sense of drama: A guide to classroom practice. Oxford: Heinemann Educational Publishers.

O'Neil, C. 1995. Drama Worlds: A framework for process drama. Portsmouth, NH: Heinemann.

O'Toole, J. 1992. The process of drama: Negotiating art and meaning. London: Routledge. Risk, P. 1993. People-based interpretation. In Manual of Heritage Management, ed. R. Harrison, 320-30. Oxford: Butterworth-Heinemann Ltd and the Association of Independent Museums.

Risnicoff de Gorgas, M. 2001. Reality as illusion, the historic houses that become museums. Museum International (UNESCO Paris) 53, 2:10-15.

Robertshaw, A. 2006. Live interpretation. In Heritage Interpretation, ed. A. Hems and M. Blockey, 41-54. London: Routledge.

Robinson, C., and M. Kellett. 2004. Power. In Doing research with children and young people, ed. S. Fraser, V. Lewis, S. Ding, M. Kellett, and C. Robinson, 81-96. London: Sage in association with Open University.

Ruddock, J., and J. Flutter. 2003. How to improve your school: Giving pupils a voice. London: Continuum Press.

Sansom, E. 1996. Peopling the past: Current practices in archaeological site interpretation. In Archaeological Displays and the Public-Museology and Interpretation, ed. P. McManus, 113-8. London: Institute of Archaeology, University College London.

Schwandt, A.T. 2003. Constructivist, interpretivist approaches to human inquiry. In The landscape of qualitative research: Theories and issues, ed. N.K. Denzin and Y.S. Lincoln, 2nd ed., 292-331. Thousand Oaks: Sage Publications.

Smith, J. 1989. The nature of social and educational inquiry: Empiricism versus interpretation. New Jersey: Ablex Publishing Corporation.

Smith, L. 2006. Uses of heritage. London: Routledge.

Thomas, G., and M.J. Silk. 1990. An introduction to the psychology of children's drawings. New York: Harvester Wheatsheaf.

Tzibazi, V. 2009. Museum theatre: children's reading of 'first person interpretation' in 
museums. In People and their past, ed. P. Ashton and H. Kean, 163-82. Basingstoke: Palgrave Macmillan.

Wallace, T. 2007. Went the day well: Scripts, glamour and performance in war-weekends. International Journal of Heritage Studies 13, no. 3: 200-23.

Woodhead, S., and A. Tinniswood. 1996. 'Making things with your heart'. In 'No longer dead to me' Working with schoolchildren in the performing and creative arts, ed. S. Woodhead and A. Tinniswood, 4-7. London: The National Trust.

Young, L. 2007. Is there a museum in the house? Historic houses as a species of Museum. Museum Management and Curatorship 22, no. 1: 59-77. 